\title{
Aluminum Alloy Selection for In Situ Composite Production by Oxygen Blowing
}

\author{
Arkady Finkelstein ${ }^{1, *(\mathbb{D})}$, Arseny Schaefer ${ }^{1}{ }^{(-)}$and Nikolay Dubinin ${ }^{1,2}$ \\ 1 Department of Foundry Engineering and Strengthening Technologies, Ural Federal University, \\ 620002 Ekaterinburg, Russia; a.a.shefer91@gmail.com (A.S.); ned67@mail.ru (N.D.) \\ 2 Department of Heterogonous Processes, Institute of Metallurgy of the Ural Branch of the Russian Academy of \\ Sciences, 620016 Ekaterinburg, Russia \\ * Correspondence: avinkel@mail.ru; Tel.: +7-912-205-5520
}

Citation: Finkelstein, A.; Schaefer, A.; Dubinin, N. Aluminum Alloy Selection for In Situ Composite Production by Oxygen Blowing. Metals 2021, 11, 1984. https:// doi.org/10.3390/met11121984

Academic Editor: Shusen Wu

Received: 4 October 2021

Accepted: 6 December 2021

Published: 9 December 2021

Publisher's Note: MDPI stays neutral with regard to jurisdictional claims in published maps and institutional affiliations.

Copyright: (c) 2021 by the authors. Licensee MDPI, Basel, Switzerland. This article is an open access article distributed under the terms and conditions of the Creative Commons Attribution (CC BY) license (https:// creativecommons.org/licenses/by/ $4.0 /)$.

\begin{abstract}
We considered the possibility of using AlMg10, AlCu5, AlCu5Cd, AlSi12, and AlSi7Zn9 as initial alloys for in situ composites production via oxygen blowing of hydrogen pre-saturated melts as an alternative to AlSi7Fe. The production process provides the destruction of the oxide film on the melt surface. It was demonstrated that oxide film on AlMg10 alloy did not get destroyed due to the heavy thickness because of the porous structure that contributed to its kinetically based growth. Copper-bearing alloys $\mathrm{AlCu} 5$ and $\mathrm{AlCu} 5 \mathrm{Cd}$ were characterized by the low-strength oxide film and got destroyed before floating, causing the oxide porosity. Silicon-bearing alloys AlSi12 and AlSi7Zn9 provide the dense structure, which makes it clear that to understand the Pilling-Bedworth ratio for basic alloying elements is required for a non-destructed oxide void floating and shall exceed the range of 1.64-1.77. However, the oxide film in silicon-bearing alloys under investigation did not get destroyed into fine particles. AlSi7Zn9 alloy had inclusions of smaller sizes as compared to AlSi12 alloy due to the $\mathrm{ZnO}$ that embrittled the film, but which were grouped to form oxide islands. Moreover, zinc was evaporated during blowing. The mechanical properties of the produced composites were based on the alloys under investigation which were in line with their structures. A higher value of the Pilling-Bedworth ratio of impurities was required for fine crushing: The conventionally used AlSi7Fe alloy met this requirement and was therefore considered to be the optimum version.
\end{abstract}

Keywords: in situ composite; aluminum alloys; oxide film; oxygen blowing; Pilling-Bedworth ratio; oxide island; oxide pore

\section{Introduction}

In situ composite material production processes are deemed to be the most costeffective methods that offer prospects for a wider scope of application as compared to ex situ composites [1]. The composite material production process of blowing of hydrogencharged melts [2] was developed inadvertently; AlSi7 contaminated with iron (approximately $1 \% \mathrm{Fe}$ ) was used as a matrix melt. The mechanism of the composite material production implies the destruction of oxide bubbles on the surface of a melt [3]; therefore, the requirement for an oxide film of sufficient strength needs to be met to avoid premature destruction within the melt volume, on the one hand, and the film needs to contain stress concentrators to ensure film destruction on the melt surface into finest possible fragments, on the other hand. The oxide particles inside the composite prevent grain boundary sliding and ensure a high strength and a low relative elongation [2]. The mechanisms for composite material formation [3] and its properties [3-5] were studied using AlSi7Fe alloy. Such a composition is considered to be the most common aluminum secondary alloy that is not characterized by a high strength and is widely used for the production of non-critical parts. The resulting composite material allows increasing the strength of the initial alloy 
by 1.5 times [3]. However, there are many other aluminum casting alloys that have a significantly higher strength [6].

Technologies of in situ $\mathrm{Al}-\mathrm{Al}_{2} \mathrm{O}_{3}$ composite production through interaction with oxygen differ in methods of destruction of forming oxide spots. In [7], forced filtration was used in an Al-Mg system; however, the authors stated that the formed oxide particles coagulated with the formation of massive conglomerates. In the patent, which also envisages forced filtration [8], alloys are not limited, but this is probably to widen patent rights.

In the technology of in situ $\mathrm{Al}-\mathrm{Al}_{2} \mathrm{O}_{3}$ composite production using oxygen blowing with induction stirring [9], Al-1 wt.\% Mg alloy is used. The choice of a silicon-free alloy is conditioned by use of an alloy for rolling, while $\mathrm{Mg}$ is needed, as the authors state, to soften the oxide film. The Al-Mg system is the main object for investigations. The thickness of oxide inclusions $\left(\mathrm{Al}_{2} \mathrm{O}_{3}\right.$ and $\left.\mathrm{MgAl}_{2} \mathrm{O}_{4}\right)$ varies within $0.1-0.4 \mu \mathrm{m}$. The characteristic dimensions of the oxide spots are $3 \mu \mathrm{m}\left(\mathrm{Al}_{2} \mathrm{O}_{3}\right)$ and $8 \mu \mathrm{m}\left(\mathrm{MgAl}_{2} \mathrm{O}_{4}\right)$. In [10], analogous results were found for alloy $\mathrm{Al}-\mathrm{Si7}-\mathrm{Mg} 0.4$ from blowing in an electric resistance furnace. In the system Al-Zn [11], oxide film also possesses less strength due to the spinel formation therein. In the proposed technology, isotropic particles of $\mathrm{Al}_{2} \mathrm{O}_{3}$ are predominantly formed with characteristic dimensions of 0.1-0.4 $\mu \mathrm{m}$ [4], which are uniformly distributed with a mass fraction of about 5\% [3], with a small number of extended oxide spots [4], and iron is a softening element. Thus, alloying elements is necessary for softening oxide spots; however, comparison of the influence of alloying elements in melt oxidizing was not conducted. Evaluation of the alloying elements' influence on the structure and properties of the produced composites is the purpose of this investigation.

Aluminum casting alloys are subdivided into groups relative to alloying systems. This article studies the possibility of using alloys of different alloying systems. The presented paper is devoted to studying alloy systems that are widely used in practice in foundries, specifically $\mathrm{Al}-\mathrm{Cu}, \mathrm{Al}-\mathrm{Si}, \mathrm{Al}-\mathrm{Mg}$, and $\mathrm{Al}-\mathrm{Zn}-\mathrm{Si}$.

\section{Materials and Methods}

The process of sample preparation is detailed in [3]. This process involves metal melting in a silica crucible; melt saturation with hydrogen using titanium hydride (II), which is introduced into the plunger wrapped in aluminum foil; melt blowing using oxygen through a tuyere made of quartz glass until the hydrogen is completely burned; followed by melt pouring into a green sand mold to produce standard samples for mechanical properties testing (Figure 1).

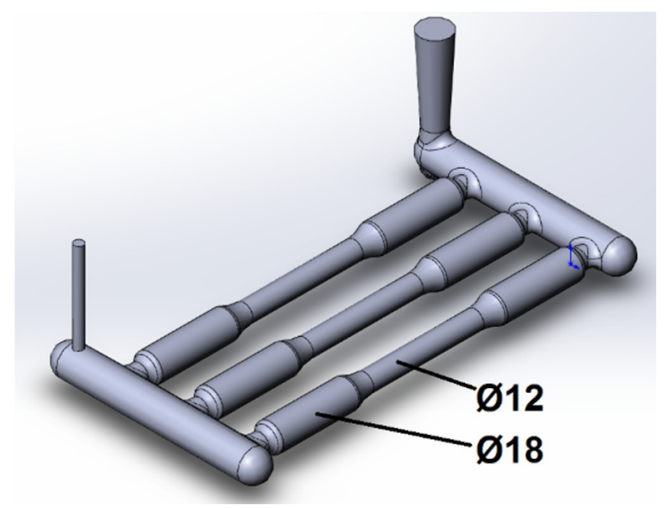

Figure 1. A $3 \mathrm{D}$ model of the experimental casting, dimensions are in $\mathrm{mm}$.

To prepare specimens, a shaft-type resistance furnace was used where a $0.5 \mathrm{~L}$ marshalite crucible was installed and a blowing tuyere of fused quartz, with an ID (inner diameter) of $6 \mathrm{~mm}$ and an OD (outside diameter) of $10 \mathrm{~mm}$ was secured. Alloys with a weight of $500 \mathrm{~g} \pm 1 \mathrm{~g}$ were used as a furnace charge. Measurements of solid substance masses were performed on AND GF-4000 and AND GR-300 scales (semi-micro analytical balances made by A\&D Company, Ltd., Tokyo, Japan). 
The alloy was overheated to $1023 \mathrm{~K} \pm 1 \mathrm{~K}\left(750{ }^{\circ} \mathrm{C} \pm 1^{\circ} \mathrm{C}\right)$. For hydrogenation of the melt, titanium hydride (II) was used. LLC Urallnvest (Russia) produced this titanium hydride (II). To prevent the release of hydrogen during its introduction, it was introduced into the melt by means of an alloying basket, wrapped in aluminum foil. Still, a portion of the hydrogen burns out as soon as it is introduced into the aluminum melt. Then the melt was blown with oxygen at a constant flowrate about $0.063 \mathrm{~m}^{3} / \mathrm{h}$ (measurement error $\pm 2.5 \%$ ) determined by means of a mass flowmeter (industrial rotameter). JSC Linde UralTechGas (Russia) produced the oxygen. The time of complete burning-out of the hydrogen was not definitely established, but was identified by an acute growth of slag on the metal mirror, which was monitored visually. As our experience shows, the time of blowing at the mentioned flowrate, until completion of hydrogen burn out, was about $1 \mathrm{~h}$.

The total sample length was $200 \mathrm{~mm}$ and the original gauge length was $60 \mathrm{~mm}$.

Samples were taken from ingots to make metallographic sections. AlCu5, AlSi12, AlMg10, and AlSi7Zn9 were tested as experimental alloys, according to standards [12] (LLC Metall-plus, Ekaterinburg, Russia) and high-strength alloy VAL10 (AlCu5Cd) (LLC Orion-Spetcsplav, Gatchina, Russia) was tested as an experimental alloy according to standards [13]. Initial chemical compositions of alloys was recorded following relevant certificates. The experiment plan included 3 heats used for test sampling. The mechanical properties of the samples were determined using an Instron 3384 tester (825 University Ave, Norwood, MA, USA). This floor model universal testing system has a measurement error $\pm 1.0 \%$. Metallographic studies of specimens were performed using an Olympus BX-51 (Shinjuku, Tokyo, Japan) optical microscope. Microstructure studies ere perfomed on a Jeol JSM-6490LV scanning electron microscope (Ltd. JEOL, Akishima, Tokyo, Japan) in the back scattered electrode mode. The chemical composition of the structural components was determined using the electron microprobe analysis method, which was performed with use of an Oxford Inca Energy 350 energy-dispersive microanalyzer (Plc Oxford Instruments, Abingdon, Oxfordshire, UK), with an accelerating voltage of 10 and $20 \mathrm{kV}$. The alloy's chemical composition before and after blowing was determined using a Spectro Midex spectrum analyzer (SPECTRO Analytical Instruments $\mathrm{GmbH}$, Kleve, Germany) with a measurement error of $\pm 0.01 \%$.

\section{Results}

The trials for blowing AlMg10 alloy failed. When oxygen blowing started, the oxide bubbles on the melt mirror failed to be destroyed, which was required for oxide particle formation; the process was implemented using AlSi7Fe alloy in [2-4]. A significant amount of slag was immediately generated on the melt mirror and the test had to be terminated.

Trial heating using the remaining alloys proved to be successful. The composite samples' chemical compositions, as compared to that of the initial alloy, are given in Tables 1-4, the mechanical properties are specified in Table 5, and photo micrographs of the structures are shown in Figures 2-5.

Table 1. Change in the chemical composition of $\mathrm{AlCu} 5$ alloy.

\begin{tabular}{cccccccc}
\hline Element & $\mathbf{S i}$ & $\mathbf{C u}$ & $\mathbf{M g}$ & $\mathbf{Z n}$ & $\mathbf{F e}$ & $\mathbf{T i}$ & $\mathbf{M n}$ \\
\hline initial & 0.113 & 4.678 & 0.04 & 0.09 & 0.2715 & 0.29 & 0.66 \\
composite & 0.269 & 4.814 & 0.033 & 0.008 & 0.282 & 0.344 & 0.701 \\
loss, \% & -138.1 & 2.9 & 17.5 & 91.1 & -3.9 & -18.6 & -6.2 \\
\hline
\end{tabular}

Table 2. Change in the chemical composition of VAL10 alloy.

\begin{tabular}{ccccccccc}
\hline Element & $\mathbf{S i}$ & $\mathbf{C u}$ & $\mathbf{M g}$ & $\mathbf{Z n}$ & $\mathbf{F e}$ & $\mathbf{C d}$ & $\mathbf{T i}$ & $\mathbf{M n}$ \\
\hline initial & 0.046 & 4.99 & 0.023 & 0.011 & 0.086 & 0.17 & 0.234 & 0.673 \\
composite & 0.22 & 5.211 & 0.025 & 0.009 & 0.106 & 0.151 & 0.306 & 0.757 \\
loss, \% & -378.3 & -4.4 & -8.7 & 18.2 & -23.3 & 11.2 & -30.8 & -12.5 \\
\hline
\end{tabular}


Table 3. Change in the chemical composition of AlSi12 alloy.

\begin{tabular}{cccccccc}
\hline Element & $\mathbf{S i}$ & $\mathbf{C u}$ & $\mathbf{M g}$ & $\mathbf{Z n}$ & $\mathbf{F e}$ & $\mathbf{T i}$ & $\mathbf{M n}$ \\
\hline initial & 12.214 & 0.256 & 0.022 & 0.28 & 0.484 & 0.051 & 0.224 \\
composite & 12.049 & 0.277 & 0.018 & 0.192 & 0.514 & 0.092 & 0.249 \\
loss, \% & 1.4 & -8.2 & 18.2 & 31.4 & -6.2 & -80.4 & -11.2 \\
\hline
\end{tabular}

Table 4. Change in the chemical composition of AlSi7Zn9 alloy.

\begin{tabular}{ccccccc}
\hline Element & $\mathbf{S i}$ & $\mathbf{C u}$ & $\mathbf{M g}$ & $\mathbf{Z n}$ & $\mathbf{F e}$ & $\mathbf{M n}$ \\
\hline initial & 6.455 & 0.41 & 0.33 & 8.2696 & 0.322 & 0.354 \\
composite & 6.582 & 0.427 & 0.189 & 5.81 & 0.347 & 0.328 \\
loss, \% & -2.0 & -4.1 & 42.7 & 29.7 & -7.8 & 7.3 \\
\hline
\end{tabular}

Table 5. Mechanical properties of initial alloys and composites.

\begin{tabular}{|c|c|c|c|c|c|c|c|c|}
\hline \multirow{2}{*}{$\begin{array}{c}\text { Mechanical } \\
\text { Properties }\end{array}$} & \multicolumn{2}{|c|}{$\mathrm{AlCu} 5$} & \multicolumn{2}{|c|}{ VAL10 } & \multicolumn{2}{|c|}{ AlSi12 } & \multicolumn{2}{|c|}{ AlSi7Zn9 } \\
\hline & Initial Alloy & Composite & Initial Alloy & Composite & Initial Alloy & Composite & Initial Alloy & Composite \\
\hline Tensile strength & 178.5 & 123.6 & 201.6 & 93.3 & 137.3 & 152.3 & 147.0 & 166.6 \\
\hline Yield strength & 178.5 & 92.0 & 189.0 & 84.3 & 110.0 & 119.3 & 121.0 & 142.6 \\
\hline $\begin{array}{l}\text { Ductility } \\
\text { (relative elongation) }\end{array}$ & 0.20 & 1.23 & 1.60 & 0.37 & 1.27 & 1.33 & 0.73 & 0.67 \\
\hline Young modulus & 2.12 & 1.61 & 3.28 & 1.69 & 1.54 & 1.72 & 1.90 & 1.88 \\
\hline
\end{tabular}

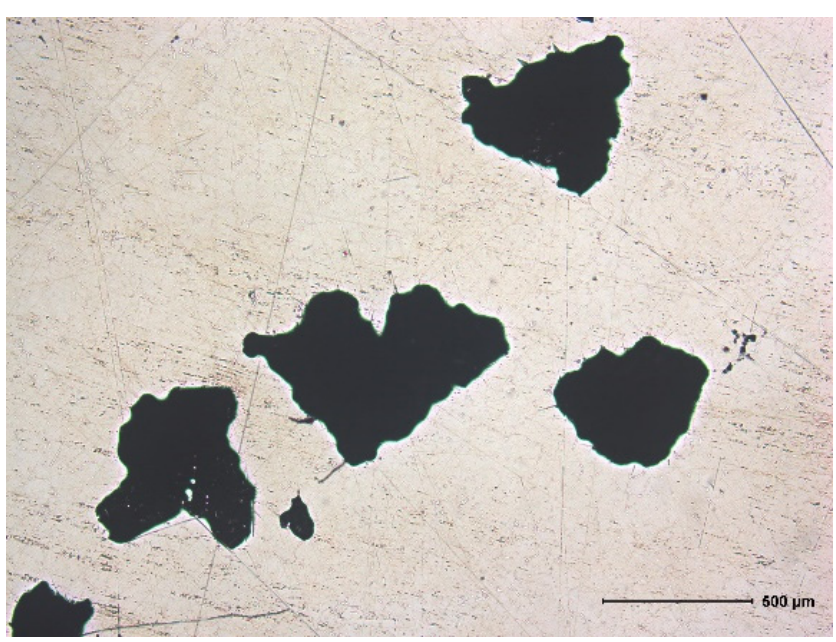

Figure 2. Cast in situ $\mathrm{AlCu} 5 / \mathrm{Al}_{2} \mathrm{O}_{3}$ composite, magnification $\times 50$.

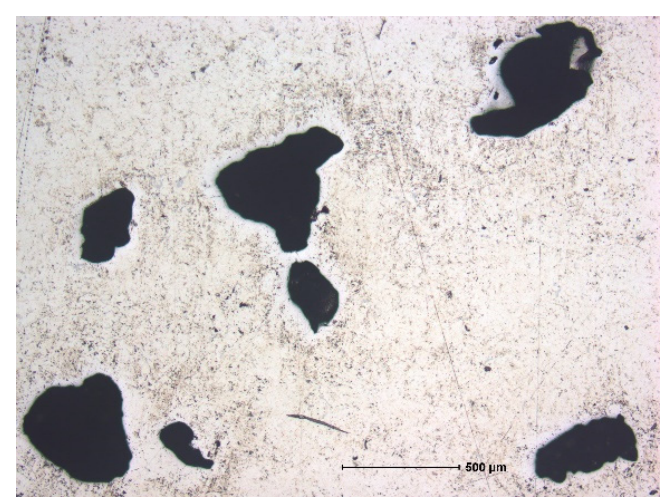

(A)

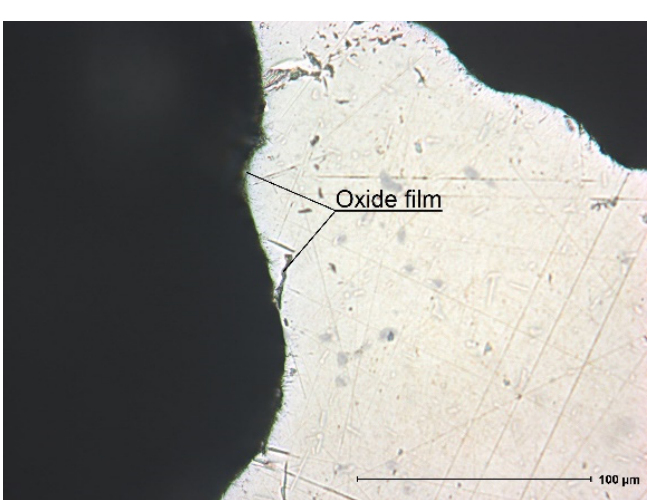

(B)

Figure 3. Cast in situ VAL10/ $\mathrm{Al}_{2} \mathrm{O}_{3}$ composite: (A) magnification $\times 50 ;($ B $)$ magnification $\times 500$. 


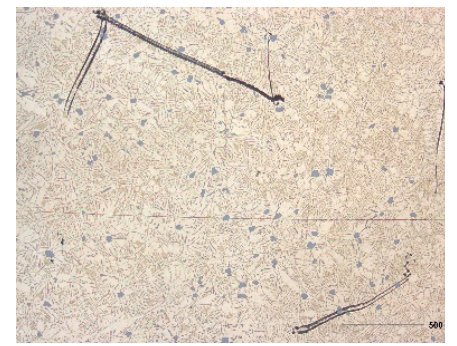

(A)

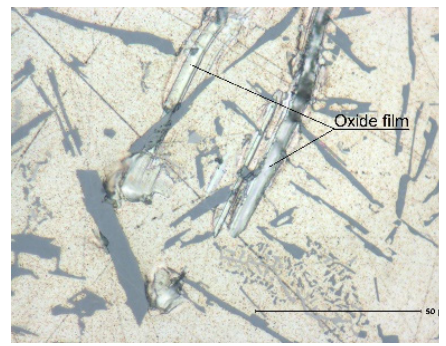

(B)

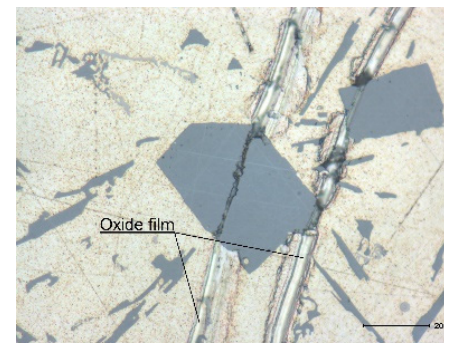

(C)

Figure 4. Cast in situ AlSi12/ $\mathrm{Al}_{2} \mathrm{O}_{3}$ composite: (A) magnification $\times 50$; (B) magnification $\times 1000$; (C) magnification $\times 1000$.

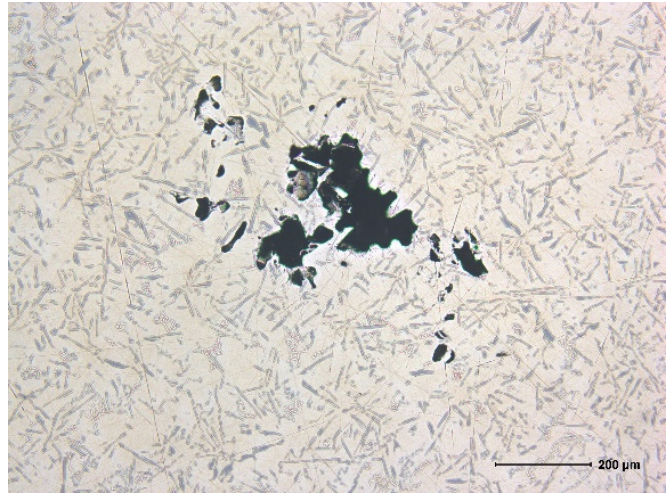

(A)

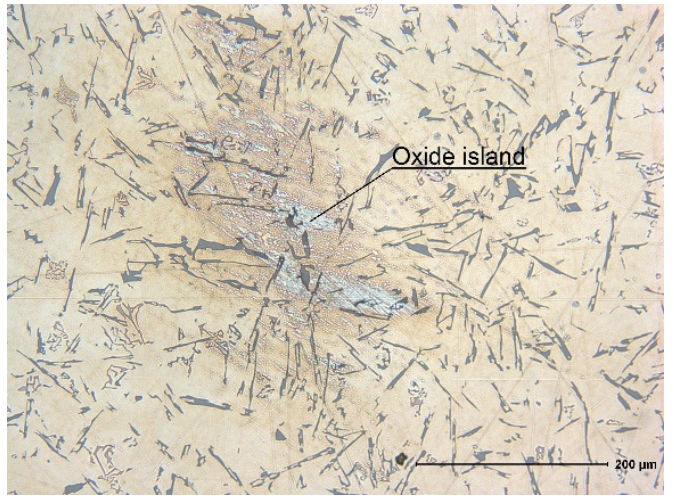

(B)

Figure 5. Cast in situ AlSi7Zn9/ $\mathrm{Al}_{2} \mathrm{O}_{3}$ composite: $(\mathbf{A})$ magnification $\times 100$; (B) magnification $\times 200$.

The chemical compositions of the structural components were determined for composites based on AlSi12 (Figures 6 and 7; Tables 6 and 7) and AlSi7Zn9 (Figure 8; Table 8).

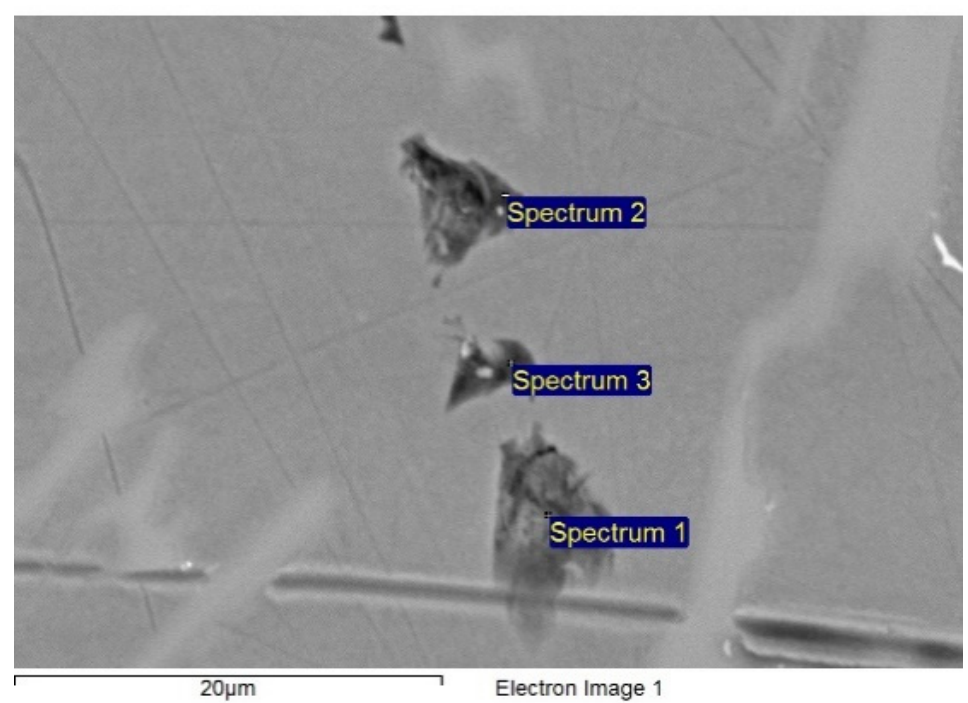

Figure 6. Electron microscopy of the composite based on AlSi12-disperse inclusions. 


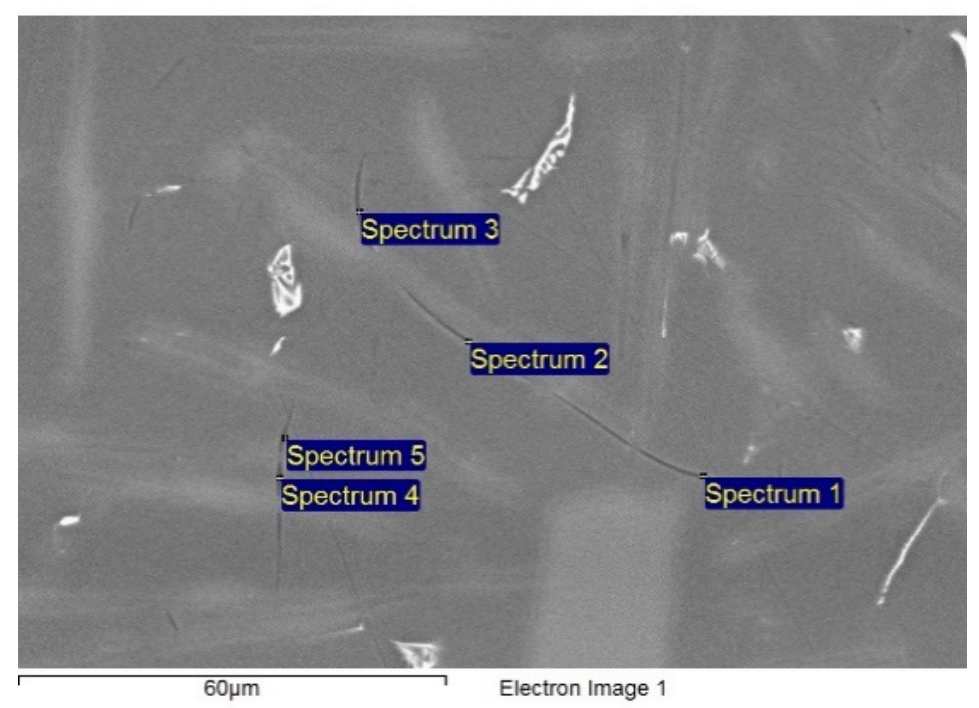

Figure 7. Electron microscopy of the composite based on AlSi12-films.

Table 6. Spectral analysis of the composite based on AlSi12.

\begin{tabular}{ccccccc}
\hline Spectrum & In Stats. & $\mathbf{O}$ & Na & Al & Si & Total \\
\hline Spectrum 1 & Yes & 8.42 & 0.40 & 84.03 & 7.14 & 100.00 \\
Spectrum 2 & Yes & 19.72 & & 60.00 & 20.27 & 100.00 \\
Spectrum 3 & Yes & 18.06 & & 63.01 & 18.93 & 100.00 \\
Max. & & 17.72 & 0.40 & 84.03 & 20.27 & \\
Min. & & 842 & 0.40 & 60.00 & 7.14 & \\
\hline
\end{tabular}

Table 7. Spectral analysis of the composite based on AlSi12-films.

\begin{tabular}{cccccc}
\hline Spectrum & In Stats. & O & Al & Si & Total \\
\hline Spectrum 1 & Yes & 0.88 & 99.12 & & 100.00 \\
Spectrum 2 & Yes & 1.29 & 89.64 & 9.08 & 100.00 \\
Spectrum 3 & Yes & 1.85 & 93.61 & 4.54 & 100.00 \\
Spectrum 4 & Yes & 1.17 & 92.57 & 6.26 & 100.00 \\
Spectrum 5 & Yes & 2.25 & 91.88 & 5.87 & 100.00 \\
Max. & & 2.25 & 99.12 & 9.08 & \\
Min. & & 0.88 & 89.64 & 4.54 & \\
\hline
\end{tabular}

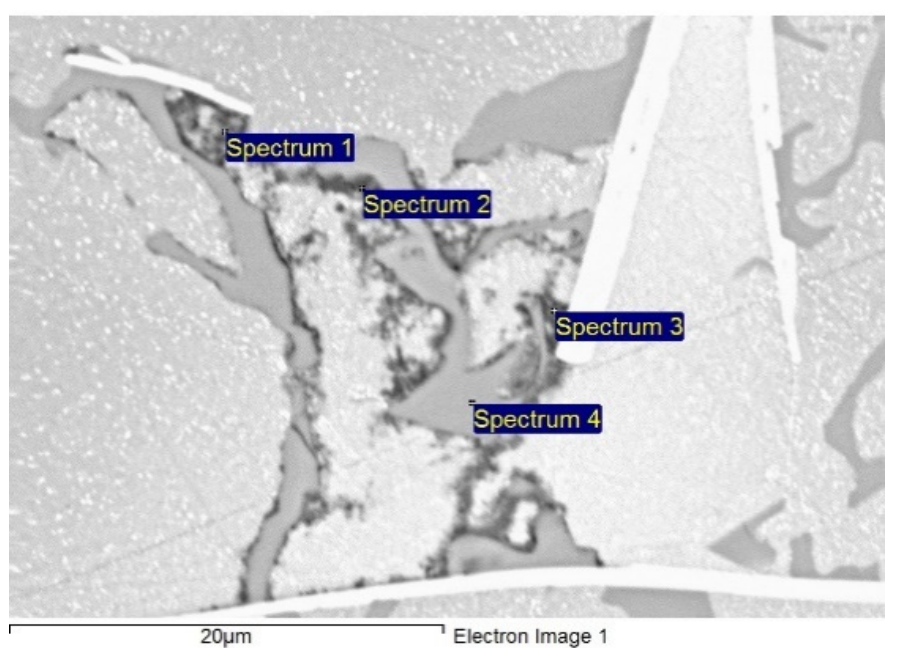

Figure 8. Electron microscopy of the composite based on AlSi7Zn9. 
Table 8. Spectral analysis of the composite based on AlSi7Zn9.

\begin{tabular}{ccccccc}
\hline Spectrum & In Stats. & O & Al & Si & Zn & Total \\
\hline Spectrum 1 & Yes & 21.07 & 58.79 & 5.26 & 14.88 & 100.00 \\
Spectrum 2 & Yes & 20.75 & 29.72 & 39.43 & 10.11 & 100.00 \\
Spectrum 3 & Yes & 18.58 & 55.95 & 10.42 & 15.05 & 100.00 \\
Spectrum 4 & Yes & & 1.15 & 98.85 & & 100.00 \\
Max. & & 21.07 & 58.79 & 98.85 & 15.05 & \\
Min. & & 18.58 & 1.15 & 5.26 & 10.11 & \\
\hline
\end{tabular}

\section{Discussion}

\subsection{Chemical Composition}

Analyses of element loss data indicate essential zinc loss (approximately 30\%). Such a significant loss is due to the fact that, during blowing, the melt gets heated up to $1000{ }^{\circ} \mathrm{C}$ [14], while the boiling point of zinc is $907^{\circ} \mathrm{C}$ [15]. However, zinc vapor pressure is quite high, even at lower temperatures [15], which results in a high loss rate when re-melting zinc-bearing alloys. Similarly, we observe cadmium loss that is characterized by a lower boiling point at $764{ }^{\circ} \mathrm{C}$ [16]. The cadmium loss rate is not that high due to its essentially lower concentration in the melt.

In the case of low silicon concentrations, a significant silicon gain is observed. This is due to the silica crucible, which undergoes an exchange reaction [17] (Equation (1)):

$$
4 \mathrm{Al}+3 \mathrm{SiO}_{2}=2 \mathrm{Al}_{2} \mathrm{O}_{3}+3 \mathrm{Si}
$$

$\mathrm{T}=1273 \mathrm{~K} ; \Delta \mathrm{H}=-675.509 \mathrm{~kJ} / \mathrm{mol} ; \Delta \mathrm{S}=-0.119 \mathrm{~kJ} / \mathrm{mol} \cdot \mathrm{K} ;$ and $\Delta \mathrm{G}=-524.068 \mathrm{~kJ} / \mathrm{mol}$.

This reaction results in melt saturation with silicon to some extent-about $+0.2 \%$. However, application of the silica crucible is determined for technical reasons: a graphite crucible burns under oxygen flow at temperatures above $1000{ }^{\circ} \mathrm{C}$, while a corundum crucible bursts due to the significant thermal stresses associated with the temperature gradient in the crucible. A high titanium gain is due to its introduction into the melt as part of hydride. A minor general gain of other elements is basically related to predominantly aluminum oxidation during melt blowing using oxygen in accordance with calculated Gibbs energies (Table 9) at $1000{ }^{\circ} \mathrm{C}$ according to data [17].

Table 9. Calculation of Gibbs energy of alloy components' oxidation.

\begin{tabular}{cccc}
\hline Oxide & $\boldsymbol{\Delta H}$ & $\boldsymbol{\Delta} \mathbf{S}$ & $\boldsymbol{\Delta} \mathbf{G}$ \\
\hline$(\mathrm{Units})$ & $\mathrm{kJ} / \mathrm{mol}$ & $\mathrm{kJ} / \mathrm{mol} \cdot \mathrm{K}$ & $\mathrm{kJ} / \mathrm{mol}$ \\
$\mathrm{Al}_{2} \mathrm{O}_{3}$ & -3384.40 & -0.65 & -2559.85 \\
$\mathrm{Fe}_{2} \mathrm{O}_{3}$ & -1619.30 & -0.53 & -939.62 \\
$\mathrm{CuO}$ & -296.11 & -0.16 & -90.88 \\
$\mathrm{MgO}$ & -1216.98 & -0.23 & -927.93 \\
$\mathrm{ZnO}$ & -773.83 & -0.54 & -90.19 \\
$\mathrm{CdO}$ & -826.65 & -0.48 & -215.36 \\
$\mathrm{SiO}_{2}$ & -919.66 & -0.18 & -694.78 \\
\hline
\end{tabular}

In the case of minor absolute values of elements concentrations, the values of loss or gain are insignificant due to possible fluctuations and measuring errors.

Changes in alloy chemical compositions when the production process is implemented restrain the use of alloys containing highly volatile elements, such as zinc, and require considering the silicon gain rate due to the use of silicon-bearing linings. 


\subsection{Oxide Films Strength: Theory}

The oxide film strength, which identifies the possibility of implementing the production process, is determined by its structure, composition, and thickness. All these factors grant the function of alloy compositions. The oxide film composition determines its defect rate, which can be roughly estimated using the Pilling-Bedworth ratio [18]: $\left(\alpha=\mathrm{V}_{\mathrm{ox}} / \mathrm{V}_{\mathrm{Me}}\right)$-the ratio of the formed oxide volume or any other compound volume to the volume of the metal consumed to form the metal oxide is calculated as per the following formula (Equation (2)):

$$
\alpha=\mathrm{V}_{\mathrm{ox}} / \mathrm{V}_{\mathrm{Me}}=\mathrm{M}_{\mathrm{ox}} * \rho_{\mathrm{Me}} /\left(\mathrm{n} * \mathrm{~A}_{\mathrm{Me}} * \rho_{\mathrm{ox}}\right),
$$

where:

$\mathrm{V}_{\text {ox }}$ - volume of the formed oxide;

$\mathrm{V}_{\mathrm{Me}}$ - volume of the metal consumed to form the oxide;

$\mathrm{M}_{\mathrm{ox}}$ - molar weight of the formed oxide;

$\rho_{\mathrm{Me}}$-metal density;

$\mathrm{n}-$ number of metal atoms per molecule of the oxide;

$\mathrm{A}_{\mathrm{Me}}$-metal atomic mass;

$\rho_{\text {ox }}$ - density of the formed oxide.

For aluminum alloys, the most dense oxide film can be formed within the ratio range of 1.2-1.4 [18], since the basic film oxide of thermodynamically unstable $\gamma-\mathrm{Al}_{2} \mathrm{O}_{3}$ with a cubic lattice has a Pilling-Bedworth ratio of 1.29. The Pilling-Bedworth ratio characterizes the ratio of the impurity of the metal density to that of the formed oxide. In the case of a lower ratio value, the oxide is not sufficient to ensure dense coverage of the metal. In the case of a higher ratio value, the impure oxide has a larger volume than the substrate, which causes stress, destroying the film.

The composition of oxide films on aluminum alloys is the scope of the investigation below. The basic alloying component in aluminum alloys is silicon, which forms a eutectic mixture with aluminum and significantly decreases the melting point. The Al-Si system oxidation results in oxide film formation from mullite (stoichiometric composition from $3 \mathrm{Al}_{2} \mathrm{O}_{3} * 2 \mathrm{SiO}_{2}$ to $2 \mathrm{Al}_{2} \mathrm{O}_{3} * \mathrm{SiO}_{2}$ ), mullite and corundum, or only corundum. According to [19], $\mathrm{CuO}$ is formed in oxide films for Al-Cu system alloys. According to [20], when $\mathrm{Zn}$ content is more than $1 \%$, the oxide film consists mainly of $\mathrm{ZnO}$ and a small quantity of $\mathrm{ZnAl}_{2} \mathrm{O}_{4}$ for $\mathrm{Al}-\mathrm{Si}-\mathrm{Zn}$ system alloys.

The oxide film is formed on the $\mathrm{Al}-\mathrm{Mg}$ system alloy surface, and forms aluminum oxide, magnesium oxide, and a combined spinel of $\mathrm{MgAl}_{2} \mathrm{O}_{4}$; primary formation of $\mathrm{MgO}$ in the oxide film is typical for alloys with a magnesium content of more than $2 \%$ [21]. In [22], some adjustment was made to the structural composition of the oxide film, depending on the alloy composition; for AlMg1 alloys, the oxide film composition mainly included spinel $\mathrm{MgAl}_{2} \mathrm{O}_{4}$ and for $\mathrm{AlMg} 3$ and AlMg5,5 alloys, it mainly included $\mathrm{MgO}$. It is of interest to note that no aluminum oxide was found by the authors in the film composition, and this phenomenon has not been clarified.

The Pilling-Bedworth ratio (Table 10) was calculated for the abovementioned oxides; as is clear from review, there was an insignificant number of spinels in the oxide film composition in the alloys under investigation and density values at room temperature were applied. The metal density for the complex oxide was calculated using the arithmetic mean method. 
Table 10. Pilling-Bedworth ratios.

\begin{tabular}{|c|c|c|c|c|c|}
\hline Oxide & $\mathbf{M}_{\mathbf{o x}}$ & $\rho_{\mathrm{Me}}$ & $\mathbf{M}_{\mathbf{M e}}$ & $\rho_{\text {ox }}$ & $\alpha$ \\
\hline (Units) & $\mathrm{g} / \mathrm{mol}$ & $\mathrm{g} / \mathrm{cm}^{3}$ & $\mathrm{~g} / \mathrm{mol}$ & $\mathrm{g} / \mathrm{cm}^{3}$ & - \\
\hline$\gamma-\mathrm{Al}_{2} \mathrm{O}_{3}$ & 102.0 & 2.70 & 54.0 & 3.95 & 1.29 \\
\hline \multicolumn{6}{|c|}{$\mathrm{Al}-\mathrm{Si}$} \\
\hline $\begin{array}{c}3 \mathrm{Al}_{2} \mathrm{O}_{3} \\
\mathrm{SiO}_{2}\end{array}$ & 426.2 & 2.65 & 218.0 & 3.15 & 1.64 \\
\hline \multicolumn{6}{|c|}{$\mathrm{Al}-\mathrm{Fe}$} \\
\hline $\mathrm{Fe}_{2} \mathrm{O}_{3}$ & 159.7 & 7.87 & 112.0 & 5.24 & 2.14 \\
\hline \multicolumn{6}{|c|}{$\mathrm{Al}-\mathrm{Cu}$} \\
\hline $\mathrm{CuO}$ & 79.5 & 8.92 & 63.5 & 6.31 & 1.77 \\
\hline \multicolumn{6}{|c|}{$\mathrm{Al}-\mathrm{Mg}$} \\
\hline $\mathrm{MgO}$ & 40.3 & 1.74 & 24.3 & 3.58 & 0.81 \\
\hline \multicolumn{6}{|c|}{$\mathrm{Al}-\mathrm{Zn}$} \\
\hline $\mathrm{ZnO}$ & 81.4 & 7.13 & 65.4 & 5.61 & 1.58 \\
\hline
\end{tabular}

\subsection{Oxide Films Strength: Discussion}

In [23], experimental investigation of oxide film destruction on aluminum alloys, including Al-Mg system alloys, was detailed. The authors implemented a dynamic method that implied oxide film removal from a melt onto a moving frame. The frame was moved apart until the film burst; the force was recorded using a dynamometer, and the film burst pressure was calculated as the ratio of applied force and oxide film thickness. The obtained results indicated the film burst pressure growth for magnesium-containing alloys; however, the author emphasized that the results obtained were an integrated effect of multiple factors, including the process kinetics, which implies oxide film destruction, thinning, growth, and repair. The author explained the film growth strength with time for AlMg3 and AlMg5 alloys using oxide film saturation with magnesium, which could be logically explained by its thickness increase, which was related to the increase in magnesium content in the film as compared to that in the melt [22]. Another study on the oxide film burst pressure for Al-Mg system alloys [24] did not find any correlation between the magnesium content and the burst pressure. Due to the oxide high density related to the matrix metal (low Pilling-Bedworth ratio), the oxide film on the Al-Mg system alloys with a magnesium content exceeding 3\% was well permeable to oxygen. For AlMg10 alloy, kinetics rather than the diffusion nature of its growth were shown in [25]; in the case of more favorable conditions (pure oxygen and temperature of about $1000^{\circ} \mathrm{C}$ ), a significant thickness of oxide film can be provided. This is what prevents its destruction when floating.

Based on the micrographs, we can identify where the oxide film destruction occurred for the remaining systems under investigation: on the melt surface or within its volume based on oxygen-bearing phases. In the case of oxide bubbles, we can assume that the film destruction occurred within the volume of the melt: a group of small bubbles was formed from the initial bubbles as it was destroyed.

Aluminum alloys of $\mathrm{Al}-\mathrm{Si}, \mathrm{Al}-\mathrm{Cu}$, and $\mathrm{Al}-\mathrm{Si}-\mathrm{Zn}$ systems have lower strength oxide films compared to pure aluminum [23], which is obvious since any element other than aluminum causes defects in the oxide film. Since the Pilling-Bedworth ratio for these systems is higher than that of pure aluminum, the oxide film strength decrease does not get compensated for by its thickness growth due to the porous structure.

The oxide film of the Al-Cu system is not strong-the ingot structure includes multiple bubbles (Figures 2 and 3), visible to the unaided eye. The effect of the oxide film on the flowability of the Al-Si-Cu system alloys is described in [26], in particular, attention is given to the 1.5 times increase in flowability in the case of a copper content change up to $2 \%$. This cannot be caused by a change in alloy toughness, heat conductivity, and crystallization interval. The increase in copper content of up to $2 \%$ in the $\mathrm{Al}-\mathrm{Cu}$ system, or in more 
multi-component systems based on aluminum, results in a $\mathrm{CuO}$ formation that contributes to the fast growth of flowability due to the decrease in oxide film strength.

The mechanical properties of the composite (Table 2) deteriorate as a result of blowing due to the non-dense structure. Significant relative elongation indicates that the melt gets saturated with fine inclusions of oxides. The oxide film of bubbles does not get divided into dispersed particles.

For the Al-Si system, the oxide film is still strong enough that the oxide film destruction does not occur, even on the melt surface at temperatures of $700-750{ }^{\circ} \mathrm{C}$, which was implemented by the authors of [14] to manufacture aluminum foam from oxide bubbles. To ensure film destruction as a result of gaseous suboxide formation, a temperature of over $1000{ }^{\circ} \mathrm{C}[14]$ is required and is achieved as a result of hydrogen burning on the metal mirror. Micrographs prove these data; the ingot structure is dense though it contains large films (Figure 4) that are partially destroyed during grinding (Figure 4C).

Mechanical properties of the alloy (Table 5) are slightly improved, which is indicative of oxide-reinforcing particles. The alloy's relative elongation remains almost unchanged despite the embrittling oxide films. This indicates the presence of an insignificant number of disperse oxide particles. These oxide particles, as we can see from the results of SEM using EDS (Figure 6 and Table 6), possess the characteristic dimensions of $5 \mu \mathrm{m}$ and a thickness of $0.1-0.5 \mu \mathrm{m}$, which are close to the alloy chemical composition using the relation of aluminum and silicon. Only oxide films located in the plane of study are acceptable to be subjected to electron microprobe analysis if the film is located perpendicularly; due to a small thickness, we may only note an insignificant increase in oxygen content with respect to the matrix (Figure 7 and Table 7). Yet, characteristic non-linear hollows, which can be identified as massive oxide spots, are present on one sample only-the composite based on AlSi12 alloy. Additionally, multiple linear scratches are present on all metallographic samples and the mentioned scratches occur from fine oxide particles during the process of grinding.

For the Al-Si-Zn system alloy, film destruction also occurs on the melt mirror, which is indicated by the insignificant oxide porosity (Figure 5A). The ingot structure is mainly dense. Oxides in the structure are grouped into oxide islands (Figure 5B), which occur as a result of oxide film division into minor fragments. These oxide islands are clusters of double films. The only detected pore is the result of the initial void destruction within the melt volume; however, the shape of the void indicates the presence of stress concentrators in the film, which are evidently zinc oxides.

The mechanical properties of the alloy are also improved; however, this is not caused by oxide-dispersed particles, but rather by oxide islands with an average size of $200 \mu \mathrm{m}$, consisting of oxide films. The relative elongation remains almost unchanged. SEM and EDS studies of the metallographic sample micro-photo images (Figure 8, Table 8) demonstrated a wide range of oxide particle sizes in "islands", with their thicknesses maintained, from isotropic $(0.1-0.5 \mu \mathrm{m})$ to $5 \mu \mathrm{m}$. Oxide films cover silicon crystals similarly to the results obtained in [5].

Based on test result analysis, it is possible to determine the critical value of the PillingBedworth ratio for the basic alloying element, required to prevent destruction of oxide bubbles during floating. This value is within the range of 1.64-1.77; however, upon bubble floating, it is destroyed to make the finest possible fragments, otherwise, structures of double films and oxide islands can be produced. To do this, the oxide film needs to contain weakening components with a maximum Pilling-Bedworth ratio in a small amount. Ironbearing alloys have such an effect on films. In Al-Fe systems, when the iron content is up to $0.25 \%$, formation of magnetite $\left(\mathrm{Fe}_{3} \mathrm{O}_{4}\right)$ or hematite $\left(\mathrm{Fe}_{2} \mathrm{O}_{3}\right)$ in the film is insignificant and intermediate spinel-hercynite $\left(\mathrm{FeAl}_{2} \mathrm{O}_{4}\right)$ is formed [27] with a density close to that of $\gamma-\mathrm{Al}_{2} \mathrm{O}_{3}\left(3.8 \mathrm{~g} / \mathrm{cm}^{3}\right)$, which is why it does not result in critical stresses in the film. In the case of a larger iron content, iron oxides are mainly found in the oxide film. Therefore, the $\mathrm{Al}-\mathrm{Si}$ system is considered to be the best option for in situ composite production with an iron content above $0.25 \%$. This is this composition that is deemed typical for 
aluminum secondary alloys as they tend to accumulate iron during re-melting. This, this very composition was used in [2-5].

\section{Conclusions}

The possibility of using alternative AlSi7Fe alloys, namely AlMg10, AlCu5, AlCu5Cd, AlSi12, and AlSi7Zn9, to produce in situ composites using hydrogen-pre-saturated melts with blowing using oxygen was studied. The technology of composite material production implies the destruction of oxide bubbles on the surface of a melt. In the Al-Mg system, the oxide film is not destroyed on the melt surface due to its significant thickness. In the $\mathrm{Al}-\mathrm{Cu}$ system, the oxide film is weak and is destroyed when bubbles float in the volume of the melt, forming oxide porosity. In the Al-Si system, destruction of the oxide film on the melt surface is achieved in accordance with the technology. Yet, a maximum dispersity of the strengthening oxide component is required for the maximum strengthening, which is achieved by presence of a small amount of softening alloying elements in the oxide film. When softening elements in AlSi12 alloy are absent, the dimensions of the oxide spots are large. The influence of the alloying elements on the oxide inclusion dispersity correlates with strength of the oxide film and can be evaluated using the Pilling-Bedworth ratio: zinc exercises a significantly lesser influence than iron; moreover, zinc gets intensely reduced in smelting in the process of blowing. According to the analysis given, the AlSi7Fe system conventionally used in this production process is deemed to be the most efficient.

Author Contributions: A.F. provided the methodology and wrote the manuscript, A.S. provided experimental information, N.D. provided data analysis. All authors have read and agreed to the published version of the manuscript.

Funding: This research received no external funding.

Institutional Review Board Statement: Not applicable.

Informed Consent Statement: Not applicable.

Data Availability Statement: Data is contained within the article.

Acknowledgments: The Laboratory for structural methods of analysis and properties of materials and nanomaterials of Shared Research Center of Ural Federal University supported SEM and EDS investigations.

Conflicts of Interest: The authors declare no conflict of interest.

\section{References}

1. Rana, R.S.; Purohit, R.; Das, S. Review of recent studies in Al matrix composites. Int. J. Sci. Eng. Res. 2012, 3, 1-16.

2. Finkelstein, A.B.; Schaefer, A.; Chikova, O.A. Microstructures, mechanical properties ingot AlSi7Fe1 after blowing oxygen through melt. Acta Metall. Slovaca 2017, 23, 4-11. [CrossRef]

3. Finkelstein, A.; Schaefer, A.; Dubinin, N. Dehydrogenation of AlSi7Fe1 Melt during In Situ Composite Production by Oxygen Blowing. Metals 2021, 11, 551. [CrossRef]

4. Chikova, O.A.; Finkel'shtein, A.B.; Shefer, A.A. Structure and Nanomechanical Properties of the Al-Si-Fe Alloy Produced by Blowing the Melt with Oxygen. Phys. Met. Metallogr. 2018, 119, 685-690. [CrossRef]

5. Finkelstein, A.B.; Shak, A.V.; Schaefer, A.A. Corrosion of an Aluminum Matrix Composite in situ Based on Al-7Si-1Fe Alloy. Russ. J. Non-Ferr. Met. 2020, 61, 108-111. [CrossRef]

6. Hatch, J.E. (Ed.) Properties of Pure Aluminum. In Aluminum Properties and Physical Metallurgy; ASM International: Metals Park, OH, USA, 1984; pp. 1-24. [CrossRef]

7. Wang, Y.; Li, H.T.; Fan, Z. Oxidation of aluminium alloy melts and inoculation by oxide particles. Trans. Indian Inst. Met. 2012, 65, 653-661. [CrossRef]

8. Newkirk, M.S.; Dizio, S.F. Novel Ceramic Materials and Methods for Making Same No. 4713360. Available online: https: / / patents.google.com/patent/US4713360A/en (accessed on 22 November 2021).

9. Ji, Y.; Gao, X.; Zhong, T. Formation and microstructure of an in situ aluminum composite by oxygen spray technique. J. Mater. Eng. Perform 1999, 8, 168-170. [CrossRef]

10. Nayebi, B.; Divandari, M. Characteristics of dynamically formed oxide films on molten aluminium. Int. J. Cast Met. Res. 2012, 25, 270-276. [CrossRef] 
11. Taheri Bagh, N.; Divandari, M.; Shahmiri, M.; Akbarifar, M. Characteristics of dynamically formed oxide films in Al-Zn melt. Int. J. Met. 2021, 15, 747-762. [CrossRef]

12. Aluminium Casting Alloys. Specifications No. 1583. Available online: http://docs.cntd.ru/document/gost-1583-93 (accessed on 1 October 2021).

13. Aluminium Cast Alloys Ingots. Specifications No. 90377. Available online: https://oboronstal.ru/wp-content/uploads/2020/0 3/ost_1_90377-87-oboronstal.ru_.pdf (accessed on 1 October 2021).

14. Finkelstein, A.; Schaefer, A.; Chikova, O.; Borodianskiy, K. Study of Al-Si Alloy Oxygen Saturation on Its Microstructure and Mechanical Properties. Materials 2017, 10, 786. [CrossRef]

15. Kaye, G.W.C.; Laby, T.H. Tables of Physical and Chemical Constants, and Some Mathematical Functions, 16th ed.; NPL: Bushy Park, UK, 1995.

16. Baker, E.H. The boiling-point relations of cadmium and zinc at elevated pressures. Int. J. Appl. Chem. 1966, 11, 321-324. [CrossRef]

17. Linstrom, P.J.; Mallard, W.G. The NIST Chemistry WebBook: A chemical data resource on the internet. J. Chem. Eng. Data 2001, 46, 1059-1063.

18. Pilling, N.B.; Bedworth, R.E. The Oxidation of Metals at High Temperatures. J. Inst. Met. 1923, $29,529-591$.

19. Cornette, P.; Zanna, S.; Seyeux, A.; Costa, D.; Marcus, P. The native oxide film on a model aluminium-copper alloy studied by XPS and ToF-SIMS. Corros. Sci. 2020, 174, 108837. [CrossRef]

20. Zhao, J.; Chai, H.; Zhang, F. Formation of Al2O3/Al Composites by Directed Melt Oxidation of Al-Si-Zn Alloy. J. Mater. Eng. Perform. 2010, 19, 46-51. [CrossRef]

21. Cochran, C.N.; Belitskus, D.L.; Kinosz, D.L. Oxidation of aluminum-magnesium melts in air, oxygen, flue gas, and carbon dioxide. Metall. Trans. B 2020, 8, 323-332. [CrossRef]

22. Akbarifar, M.; Divandari, M.; Boutorabi, S.M.A.; Ha, S.H.; Yoon, Y.O.; Kim, S.K. Short-Time Oxidation of Al-Mg in Dynamic Conditions. Oxid. Met. 2020, 94, 409-429. [CrossRef]

23. Kahl, W.; Fromm, E. Examination of the strength of oxide skins on aluminum alloy melts. Metall. Trans. B 1985, 16, 47-51. [CrossRef]

24. Syvertsen, M. Oxide skin strength on molten aluminum. Metall. Mater. Trans. B 2006, 37, 495-504. [CrossRef]

25. Azarmehr, S.A.; Divandari, M.; Arabi, H. Investigation on thickness of short time oxide films in $\mathrm{Al}-1 \mathrm{Mg}$ and $\mathrm{Al}-2 \mathrm{Mg}$ alloys. Mater. Sci. Technol. 2012, 28, 1295-1300.

26. Opie, W.R.; Grant, N.J. Hydrogen solubility in aluminum and some aluminum alloys. JOM 1950, 2, 1237-1241. [CrossRef]

27. Norman, N. The Fourier transform method for normalizing intensities. Acta Crystallogr. 1957, 10, 370-373. [CrossRef] 